\title{
PELAKSANAAN SEKOLAH INKLUSI DI INDONESIA
}

\author{
Oleh: \\ Indah Permata Darma, \& Binahayati Rusyidi \\ E-mail: \\ (indahpermatadarma@gmail.com; titi.rusyidi06@gmail.com)
}

\begin{abstract}
ABSTRAK
Sekolah inklusi merupakan salah satu bentuk pemerataan dan bentuk perwujudan pendidikan tanpa diskriminasi dimana anak berkebutuhan khusus dan anak-anak pada umumnya dapat memperoleh pendidikan yang sama. Pendidikan inklusi merupakan bentuk pelayanan pendidikan khusus yang mensyaratkan agar semua anak berkebutuhan khusus dapat menerima pendidikan yang setara dikelas biasa bersama teman-teman usianya.

Selama ini anak - anak yang memiliki perbedaan kemampuan (difabel) disediakan fasilitas pendidikan khusus disesuaikan dengan derajat dan jenis difabelnya yang disebut dengan Sekolah Luar Biasa (SLB). Secara tidak disadari sistem pendidikan SLB telah membangun tembok eksklusifisme bagi anak - anak yang berkebutuhan khusus.

Penyelenggaraan sekolah inklusi bagi anak berkebutuhan khusus hendaknya menciptakan lingkungan yang menyenangkan, ramah dan dapat menumbuhkan rasa percaya diri siswa berkebutuhan khusus untuk mengenyam pendidikan yang layak sesuai dengan hak mereka.

Kenyataan penyelenggaran sekolah inkusi di Indonesia masih belum sesuai dengan konsep yang dikemukakan dan pedoman penyelenggaraan, baik dari segi siswa, kualifikasi guru, sarana dan prasarana, dukungan orang tua dan masyarakat. Penyelenggaraan sekolah inklusi di Indonesia saat ini masih menjadi fenomena.

Kata Kunci: layanan sekolah inklusi, anak berkebutuhan khusus, sekolah inklusi
\end{abstract}

\section{Pendahuluan}

Pendidikan merupakan hak dasar setiap warga Negara Indonesia, tak terkecuali mereka yang berkebutuhan khusus. Seperti halnya dalam Undang-Undang Nomor 20 Tahun 2003 pada Pasal 5 Ayat 1, bahwa setiap warga negara mempunyai hak yang sama untuk memperoleh pendidikan yang bermutu. Peran pemerintah dalam penyelenggaraan pendidikan yang merata tentu sangat berpengaruh dan penting dalam pengembangan pendidikan. Selama ini Anak Berkebutuhan khusus disediakan fasilitas pendidikan khusus disesuaikan dengan derajat dan jenis kekhususannya yang disebut dengan Sekolah Luar Biasa (SLB). Namun, Sekolah Luar Biasa (SLB) masih menjadi tembok pemisah bagi anak-anak berkebutuhan khusus dengan anak-anak pada umumnya, hal ini menghambat proses interaksi di antara mereka. Akibatnya anak berkebutuhan khusus menjadi kelompok yang tersingkirkan dalam interaksi sosialnya di masyarakat. Masyarakat menjadi tidak akrab dengan anak berkebutuhan khusus, dan begitupun sebaliknya, anak berkebutuhan khusus merasa bukan bagian dari kehidupan masyarakat disekitarnya.

Sekolah inklusi merupakan salah satu bentuk pemerataan dan bentuk perwujudan pendidikan tanpa diskriminasi dimana anak berkebutuhan khusus dan anak-anak pada umumnya dapat 
memperoleh pendidikan yang sama. Dalam pendidikan inklusi anak berkebutuhan khusus tidak mendapat perlakuan khusus ataupun hak-hak istimewa, melainkan persamaan hak dan kewajiban yang sama dengan peserta didik lainnya. Kerjasama dari berbagai pihak baik itu pemerintah, pihak sekolah, dan masyarakat sangat berpengaruh dalam pelaksaannya, karena sekolah inklusi merupakan tantangan baru bagi pihak sekolah dan masyarakat. Dengan pelaksanaan sekolah inklusi ini diharapkan mampu menciptakan generasi penerus yang dapat memahami dan menerima segala bentuk perbedaan dan tidak menciptakan diskriminasi dalam kehidupan masyarakat kedepannya.

\section{Pembahasan}

Pendidikan inklusi telah disepakati oleh banyak negara untuk diimplementasikan dalam rangka memerangi perlakuan diskriminatif di bidang pendidikan. Implementasi pendidikan inklusi didasari oleh dokumen-dokumen internasional, yaitu Deklarasi Universal Hak Asasi Manusia tahun 1948, Konvensi PBB tentang Hak Anak tahun 1989, Deklarasi Dunia tentang Pendidikan untuk Semua, Jomtien tahun 1990, Peraturan Standar tentang Persamaan Kesempatan bagi para Penyandang Cacat tahun 1993, Pernyataan Salamanca dan Kerangka Aksi tentang Pendidikan Kebutuhan Khusus tahun 1994.

Pendidikan inklusi menurut beberapa ahli mempunyai pengertian yang beragam, diantarannya :

a. Tarmansyah (2009:75) mengatakan bahwa sekolah inklusi adalah sekolah yang menampung semua murid di kelas yang sama.

b. Tarmansyah (2009:76) mengemukakan bahwa pendidikan inklusi adalah penempatan anak berkelainan tingkat ringan, sedang dan berat secara penuh di kelas regular.

c. L.K.M. Marentek (2007:145) mengemukakan pendidikan inklusi adalah pelayanan pendidikan bagi peserta didik yang mempunyai kebutuhan pendidikan khusus di sekolah regular (SD, SMP, SMA, dan SMK) yang tergolong luar biasa baik dalam arti berkelainan, lamban belajar (slow learner) maupun yang berkesulitan belajar lainnya.

Saat ini Indonesia memang belum memiliki data yang akurat dan spesifik tentang berapa banyak jumlah anak berkebutuhan khusus. Menurut Kementerian Pemberdayaan Perempuan dan Perlindungan Anak, jumlah anak berkebutuhan khusus yang berhasil didata ada sekitar 1,5 juta jiwa. Namun secara umum, PBB memperkirakan bahwa paling sedikit ada 10 persen anak usia sekolah yang memiliki kebutuhan khusus. Di Indonesia, jumlah anak usia sekolah, yaitu 5 - 14 tahun, ada sebanyak 42,8 juta jiwa. Jika mengikuti perkiraan tersebut, maka diperkirakan ada kurang lebih 4,2 juta anak Indonesia yang berkebutuhan khusus. Jumlah Anak Berkebutuhan Khusus (ABK) di Indonesia ternyata cukup besar.

Pendidikan merupakan kebutuhan dasar setiap manusia untuk menjamin keberlangsungan hidupnya agar lebih bermartabat. Karena itu negara memiliki kewajiban untuk memberikan pelayanan pendidikan yang bermutu kepada setiap warganya tanpa terkecuali termasuk mereka yang berkebutuhan khusus seperti yang tertuang pada UUD 1945 pasal 31 (1). Namun sayangnya sistem pendidikan di Indonesia belum mengakomodasi keberagaman, sehingga menyebabkan munculnya segmentasi lembaga pendidikan yang berdasar pada perbedaan agama, etnis, dan bahkan perbedaan kemampuan baik fisik maupun mental yang dimiliki oleh siswa. Jelas segmentasi lembaga pendidikan ini telah menghambat para siswa untuk dapat belajar menghormati realitas keberagaman dalam masyarakat. Pemerintah Indonesia telah berupaya mengimplementasikan pendidikan inklusi melalui berbagai program dan kegiatan yang dilaksanakan oleh Departemen Pendidikan Nasional dan Dinasdinas pendidikan di provinsi, Kota/Kabupaten. Dalam praktiknya, implementasi pendidikan inklusi menemui berbagai kendala dan tantangan. Kendala tersebut yang sering dilaporkan adalah kesalahan pemahaman tentang konsep pendidikan inklusi, peraturan atau kebijakan yang tidak konsisten, sistem pendidikan yang tidak luwes dan sebagainya. 
Pendidikan inklusi adalah suatu kebijakan pemerintah dalam mengupayakan pendidikan yang bisa dinikmati oleh setiap warga Negara agar memperoleh pemerataan pendidikan tanpa memandang anak berkebutuhan khusus maupun anak-anak pada umumnya agar bisa bersekolah dan memperoleh pendidikan yang layak dan berkualitas untuk masa depan kehidupannya.

Strategi, metode, atau cara mengimplementasikan pendidikan inklusif di masing-masing negara sangat bervariasi (UNESCO, 200; Stubbs, 2002). Keberagaman implementasi ini disebabkan karena tiap-tiap negara memiliki budaya dan tradisi yang berbeda. Di samping itu, perbedaan implementasi ini juga terjadi di tingkat provinsi, kota, bahkan sekolah.

Upaya memperkenalkan dan mengimplementasikan pendidikan inklusi di Indonesia telah dimulai sejak tahun 1980-an. Kesuksesan pelaksanaan pendidikan inklusi dipengaruhi oleh banyak faktor di antaranya faktor budaya, politik, sumber daya manusia (Kwon, 2005). Keterlaksanaan pendidikan inklusi dapat dievaluasi dengan suatu indeks yang disebut index for inclusion (Ainscow, 2000). Indeks inklusi ini dibangun dari tiga dimensi, yaitu (1)dimensi Budaya (creating inclusive cultures), (2) dimensi Kebijakan (producing inclusive policies), dan (3) dimensi Praktik (evolving inclusive practices). Setiap dimensi dibagi dalam dua seksi, yaitu: Dimensi budaya terdiri atas seksi membangun komunitas (building community) dan seksi membangun nilai-nilai inklusi (establishing inclusive values). Dimensi kebijakan terdiri atas seksi pengembangan tempat untuk semua (developing setting for all) dan seksi melaksanakan dukungan untuk keberagaman (organizing support for diversity). Sedangkan dimensi praktik terdiri atas seksi belajar dan bermain bersama (orchestrating play and learning) dan seksi mobilisasi sumber-sumber (mobilizing resources).

Pasal 11 ayat 1 dan 2 tentang hak dan kewajiban pemerintah dan pemerintah daerah sebagai berikut:

"Pemerintah dan pemerintah daerah wajib memberikan layanan dan kemudahan, serta menjamin terselenggaranya pendidikan yang bermutu bagi setiap warga negara tanpa diskriminasi"

"Pemerintah pusat dan pemerintah daerah wajib menjamin tersedianya dana guna terselenggaranya pendidikan bagi setiap warga negara yang berusia 7-15 tahun”.

Undang-Undang di atas menunjukkan bahwa semua anak usia sekolah harus memperoleh pendidikan yang layak dan bermutu, serta pendidikan untuk semua (education for all). Kemajuan suatu bangsa dapat dilihat dari bagaimana proses pendidikan yang ada di dalamnya kemudian tertuang dalam kebijakan-kebijakan pemerintah yang diambil dalam penyelenggaraan pendidikan. Salah satunya adalah anak berkebutuhan khusus yang harus mendapat perlakuan sama dalam memperoleh pendidikan yang layak dan bermutu.

Dalam perkembangannya pendidikan anak berkebutuhan khusus telah banyak mengalami perubahan yaitu pada awalnya pendidikan anak berkebutuhan khusus bersifat segregasi atau terpisah dari masyarakat pada umumnya. Dalam pelaksanaan pendidikannya seperti sekolah SLB yang di dalamnya terdapat spesialisasi-spesialisasi terhadap anak berkebutuhan khusus sesuai dengan hambatanya seperti: SLB-A untuk sekolah anak tuna netra, SLB-B untuk sekolah anak tunarungu, SLB-C untuk sekolah anak tunagrahita, SLB-D untuk sekolah anak tunadaksa. Selanjutnya menuju pada pendidikan integratif, atau dikenal dengan pendekatan terpadu yang mengintegrasikan anak luar biasa masuk ke sekolah reguler, namun masih terbatas pada anak-anak yang mampu mengikuti kurikulum di sekolah tersebut dan kemudian inklusi yaitu konsep pendidikan yang tidak membedakan keragaman karakteristik individu.

Selama ini anak berkebutuhan khusus disediakan fasilitas pendidikan khusus yang disesuaikan dengan derajat dan jenis kebutuhannya yang disebut dengan Sekolah Luar Biasa (SLB). Secara tidak disadari sistem pendidikan SLB telah membangun tembok eksklusifisme bagi anak anak yang berkebutuhan khusus. Tembok eksklusifisme tersebut selama ini tidak disadari telah menghambat proses saling mengenal antara anak berkebutuhan khusus dengan anak - anak pada umumnya. Akibatnya dalam interaksi sosial di masyarakat kelompok berkebutuhan khusus menjadi 
komunitas yang teralienasi dari dinamika sosial di masyarakat. Masyarakat menjadi tidak akrab dengan kehidupan kelompok berkebutuhan khusus. Sementara kelompok berkebutuhan khusus sendiri merasa keberadaannya bukan menjadi bagian yang integral dari kehidupan masyarakat di sekitarnya.

Seiring dengan berkembangnya tuntutan kelompok berkebutuhan khusus dalam menyuarakan hak - haknya, maka kemudian muncul konsep pendidikan inklusi. Salah satu kesepakatan Internasional yang mendorong terwujudnya sistem pendidikan inklusi adalah Convention on the Rights of Person with Disabilities and Optional Protocol yang disahkan pada Maret 2007. Pada pasal 24 dalam Konvensi ini disebutkan bahwa setiap negara berkewajiban untuk menyelenggarakan sistem pendidikan inklusi di setiap tingkatan pendidikan. Adapun salah satu tujuannya adalah untuk mendorong terwujudnya partisipasi penuh kelompok berkebutuhan khusus dalam kehidupan masyarakat. Namun dalam prakteknya sistem pendidikan inklusi di Indonesia masih menyisakan persoalan tarik ulur antara pihak pemerintah dan praktisi pendidikan.

Meski sampai saat ini sekolah inklusi masih terus melakukan perbaikan dalam berbagai aspek, namun dilihat dari sisi idealnya sekolah inklusi merupakan sekolah yang ideal baik bagi anak dengan dan tanpa berkebutuhan khusus. Lingkungan yang tercipta sangat mendukung terhadap anak dengan berkebutuhan khusus, mereka dapat belajar dari interaksi spontan teman-teman sebayanya terutama dari aspek sosial dan emosional. Sedangkan bagi anak yang tidak berkebutuhan khusus memberi peluang kepada mereka untuk belajar berempati, bersikap membantu dan memiliki kepedulian. Disamping itu bukti lain yang ada mereka yang tanpa berkebutuhan khusus memiliki prestasi yang baik tanpa merasa terganggu sedikitpun.

Penyelenggaraan sistem sekolah inklusi merupakan salah satu syarat yang harus terpenuhi untuk membangun masyarakat inklusi. Sebuah tatanan masyarakat yang saling menghormati dan menjunjung tinggi nilai-nilai keberagaman sebagai realitas kehidupan. Banyak kasus yang muncul terkait pelaksanaan pendidikan inklusi, seperti minimnya sarana penunjang sistem pendidikan inklusi, terbatasnya pengetahuan dan keterampilan yang dimiliki oleh para guru sekolah inklusi menunjukkan bahwa sistem pendidikan inklusi belum dipersiapkan dengan baik.

Penyelenggaraan sekolah inklusi bagi anak berkebutuhan khusus seharusnya menciptakan lingkungan yang ramah terhadap pembelajaran, yang memungkinkan semua siswa dapat belajar dengan nyaman dan menyenangkan.

Penyelenggaraan sekolah inklusi memang tidak sesederhana menyelenggarakan sekolah umum. Kenyataan dilapangan dalah hal karakteristik anak berkebutuhan khusus yang diterima belum sesuai dengan kebijakan, seperti dalam hal penerimaan jenis kekhususan, tingkat kecerdasan yang masih dibawah rata, belum ada penentuan batas jumlah siswa yang diterima, serta belum memiliki sarana prasaranan khusus. Dukungan dari orangtua anak berkebutuhan khusus, orangtua siswa regular, maupun masyarakat baru berupa dukungan moral. Padahal seharusnya dukungan yang dibutuhkan berupa dukungan material maupun keterlibatan langsung dalam penyelenggaraan pendidikan inklusi. Dukungan pemerintah baik pusat maupun daerah belum merata di semua daerah dan masih sangat terbatas, baik dalam bantuan teknis (keterlibatan dalam pelaksanaan : monitoring, pembimbingan maupun evaluasi pelaksanaan pendidikan inklusi) maupun bantuan non-teknis (dana maupun peralatan).

Adapun model sekolah inklusi yang dapat dilakukan di Indonesia adalah sebagai berikut (Ashman, 1994 dalam Emawati, 2008) :

1. Kelas Reguler (Inklusi Penuh)

Anak berkebutuhan khusus belajar bersama anak normal sepanjang hari di kelas regular dengan menggunakan kurikulum yang sama.

2. Kelas regular dengan Cluster

Anak berkebutuhan khusus belajar bersama anak normal di kelas regular dalam kelompok khusus. 
3. Kelas Reguler dengan Pull Out

Anak berkebutuhan khusus belajar bersama anak normal di kelas regular namun dalam waktuwaktu tertentu ditarik dari kelas regular ke ruang lain untuk belajar dengan guru pembimbing khusus.

4. Kelas Reguler dengan Cluster dan Pull Out

Anak berkebutuhan khusus belajar bersama anak norma di kelas regular dalam kelompok khusus, dan dalam waktu-waktu tertentu ditarik dari kelas regular ke kelas lain untuk belajar dengan guru pembimbing khusus.

5. Kelas Khusus dengan Berbagai Pengintegrasian

Anak berkebutuhan khusus belajar di dalam kelas khusus pada sekolah regular, namun dalam bidang-bidang tertentu dapat belajar bersama anak normal di kelas regular.

6. Kelas Khusus Penuh Anak berkebutuhan khusus belajar di dalam kelas khusus pada sekolah regular.

\section{Penutup}

Penyelenggaraan pendidikan inklusi merupakan bentuk upaya pemerintah yang diharapkan mampu mencetak generasi penerus yang dapat memahami dan menerima segala bentuk perbedaan dan tidak menciptakan diskriminasi dalam kehidupan masyarakat ke depannya. Di beberapa kota di Indonesia pun sudah muncul sekolah inklusi yang pelaksanaannya atas kerjasama sekolah dan pemerintah kota. Akan tetapi pada kenyataannya masih sulit mewujudkan sekolah inklusi yang dapat memenuhi kebutuhan anak berkebutuhan khusus tersebut. Salah satu bentuk kesulitan tersebut adalah masih adanya masyarakat yang belum menerima adanya siswa berkebutuhan khusus di sekolah reguler, selain itu juga ketidakharmonisan antar berbagai pihak dalam pelaksanaan sekolah inklusi, seperti diperlukannya guru yang berkualitas dan pihak sekolah yang baiknya mendukung penuh pelaksanaan sekolah inklusi. Setiap pihak hendak bekerja sama dalam mewujudkan pendidikan inklusi di Indonesia dalam usaha bersama mewujudkan gagasan pendidikan tanpa diskriminasi. Pendidikan inklusi masih perlu mendapatkan perhatian khusus dalam pelaksanaannya agar supaya di masa mendatang anak berkebutuhan khususbetul-betul mendapatkan pelayanan pendidikan yang sesuai dengan kondisinya dan dapat menghormati realitas keberagaman dalam kehidupan di masyarakat secara maksimal.

\section{Daftar Rujukan}

Budhi Wibhawa, Santoso T. Raharjo, Meilany Budiarti S. 2010. Dasar-Dasar Pekerjaan Sosial, Bandung : Widya Padjadjaran.

Openshaw, Linda. 2008. Social Work In School. New York: The Guildford Press

Stubbs, Sue. 2002. Inclusive Education Where There Are Resources: The Atlas Alliance

Suparno, Edi Purwanto. Tanpa Tahun. Pendidikan Akan Kebutuhan Khusus Unit 2

Jurnal Ilmiah Pendidikan Khusus. "Proses Pembelajaran Dalam Setting Inklusi Di Sekolah Dasar.

Vol. 1, No. 1, Januari 2012

Jurnal Pendidikan Khusus. Fenomena Penyelenggaraan Pendidikan Inklusi Bagi Anak Berkebutuhan Khusus. Vol. 7, No. 2, November 2010 